in the occasional use of supposed scientific principles as a means of accounting for facts of animal structure. $\mathrm{He}$ has dealt with a subject of great difficulty with commendable clearness, and will interest readers who would be unable to follow a more technical exposition of extinct types of life.

H. G. S.

\section{ENERGY AND VISTON.}

$\mathrm{T} \mathrm{HE}$ interesting researches of Prof. S. P. Langley on energy and vision have recently been published in the Memoirs of the American National Academy of Sciences. From this we gather that he was led to investigate the question by the fact that it was not generally recognized how totally different effects may be produced by the same amount of energy in different parts of the spectrum. Two series of experiments were necessary, the first to determine the amount of energy in each ray, the second to observe the corresponding visual effect. The energy was determined as heat by the use of the bolometer, the heat dispersed by a prism being very nearly proportionate to the energy.

In the second series of experiments a beam of sunlight from a siderostat passes through a small hole in a darkened room and falls on a slit with a standard width of $0.1 \mathrm{~mm}$. It is then received on a collimating lens of I I 9 centimetres aperture and 755 centimetres focal length, after which it passes through a prism of about $60^{\circ}$ refracting angle. The spectrum thus formed is reflected and brought to a focus on a second slit of one millimetre aperture by a concave mirror, any particular colour being adjusted on the slit by a rotation of the prism. This second slit is screened from all possible stray light by a dark curtain, and is used as a source of illumination for a series of numbers from a table of logarithms, which is attached to a sliding screen. The greatest distance from the slit at which the figures could be distinctly read was then determined, and the law of inverse squares applied. For the brighter colours of the spectrum, the light entering the first slit was reduced by an adjustable photometer wheel.

Actinometric measures were made during the progress of the photometric observations, and showed a solar radiation of $\mathrm{I}^{\prime} 5$ calories per square centimetre per minute ; this naturally being an essential unit.

The energy necessary to give the bare impression of luminosity in different parts of the spectrum, expressed in terms of horse-power, was found to be roughly as follows, the minimum visibile being defined as the feeblest light which is observed to vanish and reappear when silently occulted and restored without the knowledge of the observer :-

$\begin{array}{llc}\text { Violet }(\lambda 400) & \ldots & 0.000000 \text { Oc0000 00018000 } \\ \text { Green }(\lambda 550) & \ldots & 0.000000 \text { 000000 } 00000075 \\ \text { Scarlet }(\lambda 650) & \ldots & 0.00000000000000017000 \\ \text { Crimson }(\lambda 750) & \ldots & 0.00000000000034000000\end{array}$

These values were derived from observations made by a single observer, Mr. F. W. Very, and are, of course, subject to a large percentage of error.

The general results of the investigation may be best summarized in Prof. Langley's own words :-

"The time required for the distinct perception of an excessively faint light is about one-half second. A relatively very long time is, however, needed for the recovery of sensitiveness after exposure to a bright light, and the time demanded for this restoration of complete visual power appears to be greatest when the light to be perceived is of a violet colour. The amount of energy required to make us see varies enormously according to the colour of the light in question. It varies considerably between eyes which may ordinarily be called normal ones, but an average from those of four persons gives the following proportionate result for seven points in the normal spectrum, whose wave-lengths correspond approximately with those of the ordinary colour divisions, where unity is the amount of energy required to make us see light in the extreme red of the spectrum near $\mathrm{A}$, and where the six preceding wave-lengths given correspond approximately to the six colours, violet, blue, green, yellow, orange, red.

\begin{tabular}{l|r|r|r|r|r|r|r} 
Colour & Violet & Blue & Green & Yellow & Orange & Red & Crimson \\
Wave length & 400 \\
Luminosity & 470 & 530 & 580 & 605 & 650 & 750 \\
160 & 62,000 & 100,000 & 28,000 & $x_{4} .000$ & 200 & $\mathbf{I}$ \\
\hline
\end{tabular}

It appears from this that the same amount of energy may produce at least 100,000 times the visual effect in one colour of the spectrum that it does in another.

If now it be inquired what the actual value of unity is in ordinary measure, we are able to give this also with a fair approximation, and to say that the vis-vizu of the waves whose length is 7500 (tenth meires) being arrested by the ordinary retina, represents work done in giving rise to the sensation of the deepest red light of about o'oor of an erg in one-half second.

\section{NOTES.}

The Prince of Wales has consented to become Chairman of the Committee for the memorial of the late Sir Richard Owen, and to preside at a meeting to further the object, which will be held in the rooms of the Royal Society, Burlington House, on Saturday, the 21st inst., at half-past eleven o'clock. Admission will be by tickets, which may be obtained from Mr. Percy Sladen, Linnean Society, Burlington House, W. (who is acting as secretary to the Committee), or from Mr. H. Rix, assistant secretary of the Royal Society.

THE annual general meeting of the Royal Meteorological Society will be held at 25 , Gre at George-street, Westminster, on Wednesday, the I8th instant, at 7.15 p.m., when the Report of the Council will be read, the election of officers and counci! for the ensuing year will take place, and the President (Dr. C. Theodore Williams) will deliver an address on "The High Altitudes of Colorado and their Climates," which will be illustrated by a number of lantern slides. This meeting will be preceded by an ordinary meeting, which will begin at 7 p.m.

THE general meeting of the Association for the Improvement of Geometrical Teaching is to be held at University College, Gower Street, W.C., on Saturday, January I4, the Rev. C. Taylor in the chair. At the morning sitting (II a.m.) the report of the Council will be read, the new officers will be elected, and several candidates will be proposed for election as members of the Association. After the conclusion of the formal business Mrs. Bryant will give "A Model Lesson on Geometry, as a Basis for Discussion." After an adjournment for luncheon at 1 p.m. members will re-assemble $(2$ p.m.) to hear papers by Mr. G. Heppel on "The Use of History in Teaching Mathematics," and Mr. F. E. Marshall on "The Teaching of Elementary Arithmetic." Members who wish to have any special matter brought forward at the general meeting, but who are unable to attend, are requested to communicate with one of the Honorary Secretaries. All interested in the objects of the Association are invited to attend.

Dr. LUDWrg Becker has been appointed to the chair of astronomy at the University of Glasgow.

The Comet Medal of the Astronomical Society of the Pacific Coast has been awarded to Mr. Edwin Holmes, of London, for his discovery of a new comet on November 6 .

ON Tuesday next (January 17) Prof. Victor Horsley, F.R.S., will begin a course of ten lectures, at the Royal Institution, on "The Functions of the Cerebellum and the Elementary Prin-

No. I 2 I I, vor. 47] 